\title{
Caracterização da variabilidade de genes relacionados à fertilidade de machos e ao temperamento em eqüinos da raça brasileira Mangalarga
}

\section{Characterization of the variability of genes related to male fertility and temperament in Brazilian Mangalarga horses}

\author{
Lidia Carolina Meira Arneiro ${ }^{1 *}$; Rogério Abdallah Curi²; \\ Josineudson Augusto II Vasconcelos Silva²; Marcílio Dias Silveira da Mota ${ }^{2}$
}

Resumo

\begin{abstract}
Os objetivos deste trabalho foram a padronização de metodologia de genotipagem por PCR-RFLP dos SNPs AJ_315378:c.110A $>$ G e AB_264325:c.771G $>$ C dos genes CRISP1 e HTR1A eqüino, respectivamente, bem como a caracterização em eqüinos da raça Mangalarga destes e de outro polimorfismo, o AB_098561:c.1470G $>$ A do gene SLC6A4, a fim de promover o embasamento necessário para futuras pesquisas visando associação entre marcadores de DNA e características de interesse na raça. Para tanto, foram utilizados 151 animais Mangalarga, de ambos os sexos e de idades variadas, representativos da população do estado de São Paulo. O método de PCR-RFLP mostrou-se adequado para a genotipagem dos SNPs AJ315378:c.110A $>$ G do CRISP1 e AB_264325:c.771G $>$ C do HTR1A. Entretanto, o polimorfismo do CRISP1 provavelmente não ocorre em eqüinos Mangalarga, impossibilitando estudos de associação do marcador com características relacionadas à fertilidade de machos. As estimativas dos parâmetros genético-populacionais obtidos para os polimorfismos AB_264325:c.771G>C do HTR1A e o AB_098561:c.1470G>A do SLC6A4 na amostra de animais estudados desencorajam a realização de pesquisas visando a associação entre os marcadores e características relacionadas ao temperamento.
\end{abstract}

Palavras-chave: Cavalos, CRISP1, HTR1A, polimorfismos, SLC6A4

\begin{abstract}
The aims of the present study were to propose a PCR-RFLP genotyping method for the AJ 315378:c.110A $>\mathrm{G}$ and $\mathrm{AB}$ 264325:c.771G $>\mathrm{C}$ SNPs in the equine CRISP1 and HTR1A genes, respectively, as well as to characterize these and another polymorphism, AB 098561:c.1470G $>$ A of the SLC6A4 gene, in order to provide a basis for future studies investigating the association between DNA markers and traits of interest in this breed. For this, 151 Mangalarga horses of both sexes, representatives of the population of the Sate of São Paulo, Brazil, were used. PCR-RFLP was found to be adequate for the genotyping of the SNPs AJ_315378:c.110A $>\mathrm{G}$ of the CRISP1 and AB_264325:c.771G $>$ C of the HTR 1A. However, the polymorphism of the CRISP1 probably does not occur in Mangalarga horses, a fact impairing association studies of this marker with traits related to male fertility. The estimative of the population genetic parameters obtained for the polymorphisms AB_264325:c.771G $>$ C of the HTR1A and AB_098561:c.1470G $>$ A of the SLC6A4 in the studied sample discourage the conduct of research addressed the association between markers and traits related to temperament.
\end{abstract}

Key words: CRISP1, horses, HTR1A, polymorphisms, SLC6A4

\footnotetext{
${ }^{1}$ Discente do Dept ${ }^{\circ}$ de Genética e Melhoramento Animal, Universidade Estadual Paulista, Faculdade de Ciências Agrárias e Veterinárias, UNESP, Jaboticabal, SP. E-mail: lidiacarol@ibest.com.br

${ }^{2}$ Profs. do Dept ${ }^{\circ}$ de Melhoramento e Nutrição Animal, Faculdade de Medicina Veterinária e Zootecnia, UNESP, Botucatu, SP. E-mail: rogcuri@fmvz.unesp.br; jaugusto@fmvz.unesp.br; mdsmota@fmvz.unesp.br

*Autor para correspondência
} 


\section{Introdução}

O melhoramento genético de eqüinos da raça Mangalarga tem se baseado na estimativa de parâmetros genéticos e fenotípicos apenas de características contidas nas tabelas de pontuação - conformação e andamento, avaliadas subjetivamente, e de desenvolvimento, mensuradas na ocasião do registro (MOTA; GIANNONI, 1994, MOTA; ALMEIDA PRADO, 2005, MOTA; ALMEIDA PRADO; MADUREIRA, 2006). Pouco se conhece acerca de caracteres reprodutivos e de temperamento dos animais, fundamentais em qualquer sistema de criação animal.

Características reprodutivas têm se mostrado difíceis de selecionar a partir de métodos quantitativos em todas as espécies, especialmente em eqüinos, devido suas estimativas relativamente baixas de herdabilidade e dificuldades na avaliação dos dados (TAVEIRA; MOTA, 2007). Apesar disso, a fertilidade de machos é característica econômica de larga importância devido ao aumento do uso da técnica de inseminação artificial na indústria de reprodutores de elevado valor genético. A CRISP1 (cysteine-rich secretory protein 1) é membro da família de proteínas CRISP, a qual é caracterizada pela presença de 16 resíduos de cisteína na região C-terminal.As proteínas CRISPsão expressas notrato genital masculino e estão supostamente relacionadas ao processo de fusão entre espermatozóide e óvulo, o que torna seus respectivos genes codificadores, entre os quais o CRISP1 (cysteine-rich secretory protein 1 gene - também conhecido como AEG1), mapeado no cromossomo eqüino 20, candidatos para a característica fertilidade de machos (GIESE et al., 2002).

Definido como o conjunto de características comportamentais estáveis ao longo do tempo e entre situações, o temperamento geral é qualidade fundamental no cavalo de sela. Animais com bom temperamento são obedientes, fáceis de treinar, calmos e confiáveis (EVANS, 1996). De acordo com Murphy et al. (2008), a literatura científica recente vem explicando os importantes papéis dos receptores e do transportador de serotonina nas funções que esta desempenha como neurotransmissor e neuromodulador nos processos neuroquímicos, fisiológicos, farmacológicos e comportamentais. Em espécies como a humana e a canina, genes do grupo de receptores de serotonina (HTR), localizado no cromossomo eqüino 21, entre os quais o HTR1A (5-hydroxytryptamine (serotonin) receptor 1 A gene), vêm se mostrando envolvidos em disfunções emocionais. Em eqüinos, estes genes são de especial interesse devido à suposta relação entre seus produtos protéicos e distúrbios gastrointestinais decorrentes de alterações no sistema nervoso central e periférico, uma das principais causas de morte, levando a perdas econômicas consideráveis dentro de sistemas de produção (MOMOZAWA et al., 2007). Por sua vez, o gene SLC6A4 (solute carrier family 6 (neurotransmitter transporter, serotonin), member 4 gene), mapeado no cromossomo eqüino 11, codificador do transportador de serotonina, é forte candidato a influenciar características de temperamento em animais ao atuar no controle da reabsorção da serotonina nas fendas sinápticas (MOMOZAWA et al., 2006).

Diante do exposto, os objetivos deste trabalho foram a padronização de metodologia de genotipagem por PCR-RFLP dos SNPs AJ_315378:c.110A $>$ G eAB_264325:c.771G $>$ C dos genes CRISP1 e HTR1A eqüino, respectivamente, bem como a caracterização em eqüinos da raça Mangalarga destes e de outro polimorfismo, o AB_098561:c.1470G>A do gene SLC6A4, a fim de que se tenha o embasamento necessário para futuras pesquisas visando associação entre marcadores de DNA e características relacionadas à fertilidade de machos e de temperamento na raça.

\section{Material e Métodos}

Animais e coleta de sangue

Foram utilizados 151 cavalos da raça Mangalarga registrados na Associação Brasileira dos Criadores 
de Cavalos da Raça Mangalarga (ABCCRM), de ambos os sexos e de idades variadas, representativas da população do Estado de São Paulo/Brasil. Amostras de cinco $\mathrm{mL}$ de sangue total de cada indivíduo foram colhidas por venopunção da jugular esquerda utilizando tubos a vácuo com EDTA.

\section{Extração do DNA e genotipagem}

Após a remoção das hemácias das amostras de sangue, a extração de DNA dos leucócitos foi realizada pelo método não fenólico, utilizando digestão com proteinase $\mathrm{K}$ e precipitação com $\mathrm{NaCl}$ e álcool.

A genotipagem dos polimorfismos AJ_315378:c.110A $>\mathrm{G}$ do gene CRISP1, AB_264325:c.771G $>\mathrm{C}$ do HTR1A e AB_098561:c.1470G $>$ A do SLC6A4 foram realizadas por meio da técnica de PCR-RFLP. Os primers necessários à amplificação das regiões gênicas de interesse, as enzimas de restrição utilizadas na detecção dos polimorfismos, bem como outras informações de relevância encontramse apresentados na Tabela 1.

$\mathrm{Na}$ análise do SNP AJ_315378:c.110A $>\mathrm{G}$ do CRISP1, fragmento de 910 pares de bases contendo seqüência do exon 3 foi amplificado de acordo com Giese et al. (2002). A análise in silico do mapa de restrição da região amplificada, realizada por meio do programa online Webcutter 2.0, mostrou a possibilidade de genotipagem do polimorfismo utilizando a endonuclease BseNI. Neste sentido, os amplificados foram digeridos em meio de reação contendo $12 \mu \mathrm{L}$ de produto de PCR e $5 \mathrm{U}$ da enzima BseNI (Fermentas, EUA). As misturas para digestão foram incubadas em termociclador a $65^{\circ} \mathrm{C}$ por 14 horas.
Após análise in silico do mapa de restrição da seqüência que contém o polimorfismo AB_264325:c.771G $>$ C do gene HTRlA eqüino, realizada com o Webcutter 2.0, constatou-se a possibilidade de sua genotipagem por meio da endonuclease AluI. Fragmento de 432 pares de bases da região codificante do gene foi amplificado utilizando par de primers confeccionados com auxílio do programa Primer 3 (ROZEN; SKALETSKY, 2000). A averiguação da qualidade dos óligos em relação à formação de hairpins, dímeros e dímeros cruzados foi realizada utilizando o programa NetPrimer online. A confirmação de que cada sequência iniciadora era única para o gene alvo na espécie de interesse foi realizada utilizando a ferramenta Primer-BLAST do NCBI. Cada PCR, com volume final de $25 \mu \mathrm{L}$, foi constituída de 50 ng de DNA genômico, $0,24 \mu \mathrm{M}$ de cada primer, $1,6 \mathrm{mM}$ de $\mathrm{MgCl}_{2} ; 0,24 \mathrm{mM}$ de cada dNTP e 0,5U de Taq DNA polimerase (Invitrogen, EUA). Após desnaturação inicial a $95{ }^{\circ} \mathrm{C}$ por 5 minutos, a amplificação foi realizada em 36 ciclos de $95{ }^{\circ} \mathrm{C}$ por 60 segundos, $54{ }^{\circ} \mathrm{C}$ por 45 segundos e $72{ }^{\circ} \mathrm{C}$ por 30 segundos. A extensão final foi conduzida a $72{ }^{\circ} \mathrm{C}$ por 5 minutos. Alíquotas de $10 \mathrm{~mL}$ de produtos de amplificação foram digeridas com $4 \mathrm{U}$ da enzima AluI (New England Biolabs, EUA) a $37^{\circ} \mathrm{C}$ por 16 horas.

Em relação à análise do polimorfismo AB_098561:c.1470G>A do SLC6A4, fragmento de 359 pares de bases da região codificante do gene foi amplificado e digerido com a enzima de restrição HhaI (New England Biolabs, EUA), como em Momozawa et al. (2006). 
Após a digestão dos produtos amplificados, os fragmentos de DNA dos genes CRISP1, HTR1A e $S L C 6 A 4$ foram separados em géis de agarose a 2, 2 e $3 \%$, respectivamente. Um padrão de peso molecular de 100 pares de bases foi utilizado em cada gel para permitir o cálculo do tamanho dos fragmentos amplificados e digeridos. A visualização das bandas foi realizada por meio de coloração com brometo de etídeo e exposição à luz ultravioleta. Os genótipos dos indivíduos foram determinados, para cada polimorfismo, por meio da análise do tamanho dos fragmentos em pares de bases (pb).

\section{Análise dos Dados}

Utilizando o programa PopGene 1.32 (YEH; YANG; BOYLE, 1999) foram calculados as frequências alélicas e genotípicas e o equilíbrio de Hardy Weinberg para cada um dos sítios polimórficos analisados. A neutralidade seletiva foi avaliada segundo o teste do parâmetro $F$ de EwensWatterson, com os programas Popgene 1.32 e PyPop (LANCASTER et al., 2007). As análises realizadas pelo programa Popgene 1.32 estabeleceram intervalo de confiança para $F$. O programa PyPop verificou a significância do desvio normalizado entre $F$ esperado e $F$ observado por meio do teste exato de Slatkin (SLATKIN, 1996).

\section{Resultados e Discussão}

\section{Polimorfismo do CRISPI}

Giese et al. (2002) analisaram por meio de seqüenciamento direto de produtos de PCR a ocorrência de diversidade no gene CRISP1 de eqüinos em 16 cavalos de nove raças (Hanoveriana, Haflingo, Shire-Horse, Knabstrupper, Shagya Árabe, Pôneis, Pôneis Shetland, Irish Tinker e Lusitano) e encontraram vários polimorfismos, incluindo o AJ_315378:c.110A $>$ G, estudado no presente trabalho, o qual apresenta potencial para provocar alterações fenotípicas por acarretar modificação não conservativa na seqüência de aminoácidos da 
cadeia polipeptídica. Este sítio polimórfico está localizado no éxon 3 e é responsável pela troca de um ácido glutâmico por uma glicina na posição 37 (Glu37Gli) da proteína CRISP1.

Em relação ao referido polimorfismo, apenas o alelo A foi identificado na amostra de animais estudados (Tabela 2). O genótipo AA foi caracterizado pela presença de três fragmentos de
$761,85,64$ pb, sendo que a visualização do fragmento menor não foi possível na condição de eletroforese realizada (Figura 1). Com base no mapa de restrição do fragmento amplificado, o genótipo GG seria caracterizado pela presença de quatro bandas com 552, 209, 85 e 64 pb, e o heterozigoto (AG) pela presença de cinco fragmentos, correspondentes à combinação dos padrões dos homozigotos.

Tabela 2. Frequências alélicas e genotípicas obtidas para os polimorfismos AJ_315378:c.110A $>\mathrm{G}$ do gene CRISP1, AB_264325:c.771G $>$ C do gene HTR1A e AB_098561:c.1470G $>$ A do gene SLC6A4 em amostra representativa da população de eqüinos da raça Mangalarga do Estado de São Paulo.

\begin{tabular}{lccccc}
\hline Polimorfismo & Frequência alélica & \multicolumn{3}{c}{ Frequência genotípica } & \\
\hline $\mathrm{AJ} 315378: \mathrm{c} .110 \mathrm{~A}>\mathrm{G}$ & $\mathrm{A}$ & $\mathrm{G}$ & $\mathrm{AA}$ & $\mathrm{AG}$ & $\mathrm{GG}$ \\
$(\mathrm{CR} I S P 1)$ & 1,00 & 0,00 & 1,00 & 0,00 & 0,00 \\
\hline $\mathrm{AB} 264325: \mathrm{c} .771 \mathrm{G}>\mathrm{C}$ & $\mathrm{C}$ & $\mathrm{G}$ & $\mathrm{CC}$ & $\mathrm{CG}$ & $\mathrm{GG}$ \\
$(H T R 1 A)$ & 0,02 & 0,98 & 0,00 & 0,03 & 0,97 \\
\hline $\mathrm{AB}[098561: \mathrm{c} .1470 \mathrm{G}>\mathrm{A}$ & $\mathrm{A}$ & $\mathrm{G}$ & $\mathrm{AA}$ & $\mathrm{AG}$ & $\mathrm{GG}$ \\
$($ SLC6A4) & 0,08 & 0,92 & 0,00 & 0,16 & 0,84 \\
\hline
\end{tabular}

Fonte: Elaboração dos autores.

Figura 1. Padrão de bandas obtido na análise por PCR-RFLP e eletroforese em gel de agarose a $2 \%$ para o polimorfismo AJ_315378:c.110A $>\mathrm{G}$ do gene CRISP1 eqüino. M indica o padrão molecular de 100 pb, ND DNA amplificado não digerido pela enzima $B s e N I(910 \mathrm{pb})$ e AA o genótipo decorrente da digestão dos produtos amplificados pela enzima $B s e N I$. Os números ao lado direito da figura indicam o tamanho dos fragmentos de DNA em pares de bases.

\section{ND AA}

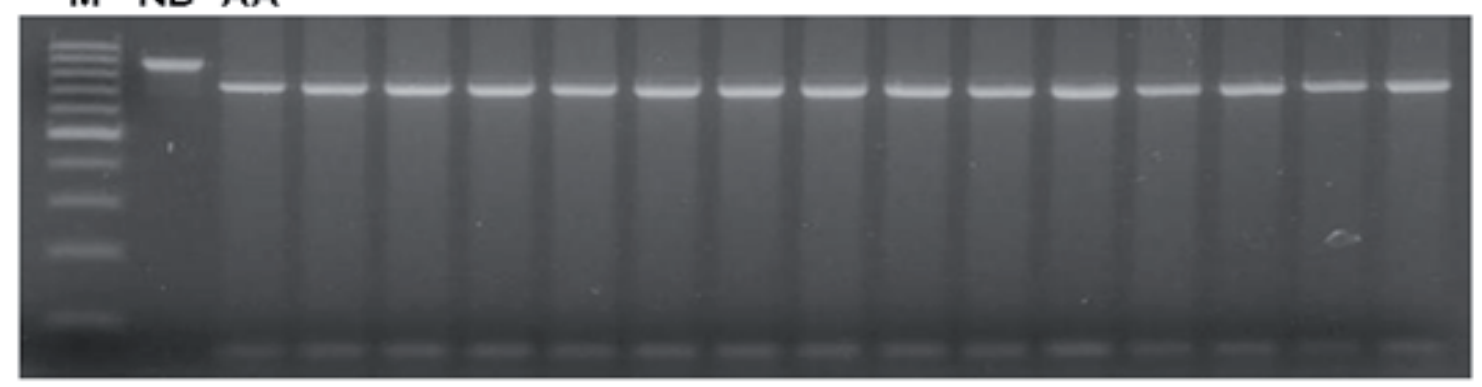

Fonte: Elaboração dos autores.

Não foram encontrados na literatura relatos de freqüências alélicas e genotípicas para o polimorfismo AJ_315378:c.110A $>\mathrm{G}$ do gene CRISP1 em eqüinos Mangalarga. Em eqüinos da raça Hanoveriana, Hamann et al. (2007) encontraram freqüências de 0,99 para o alelo A e 0,01 para o G. Os resultados aqui apresentados demonstraram a provável ausência do polimorfismo do gene CRISPI em eqüinos Mangalarga. Entre as possíveis explicações para o fato tem-se que a população 
fundadora da raça poderia ser homozigota para este loco em particular, ou que a fixação do alelo A possa ter ocorrido posteriormente em razão de seleção indireta. Entretanto, não pode ser descartada a possibilidade da rara ocorrência do alelo $\mathrm{G}$ na raça, o que poderia ser confirmado com amostragens mais amplas.

Embora a provável inexistência do SNP na Mangalarga não permita estudos de associação entre o marcador e características de importância na raça, o método de PCR-RFLP mostrou-se eficaz, de baixo custo e apropriado para laboratórios dotados de estrutura básica em equipamentos e reagentes, o que permitirá a expansão da análise desse polimorfismo nas raças em que ocorra. Entretanto, para a realização de estudos de associação com o CRISP1 na Mangalarga, faz-se necessário o estudo da segregação de outros polimorfismos já descritos para o gene ou a busca por novos na seqüência de DNA da raça. Apesar de gene candidato para a característica fertilidade de machos, não foram encontrados na literatura resultados de estudos de associação entre polimorfismos do gene CRISPl e aspectos reprodutivos em eqüinos. Em Hamann et al. (2007) a verificação de associação entre o polimorfismo AJ_315378:c.110A $>\mathrm{G}$ do gene CRISP1 e a fertilidade de garanhões da raça Hanoveriana não foi possível em virtude da extremamente baixa freqüência do alelo $G$. Por outro lado, outros genes da mesma família foram recentemente estudados com relação à suas associações com fertilidade em eqüinos e em humanos. Hamann et al. (2007) identificaram SNP não sinônimo no gene CRISP3, com efeito significativo sobre a fertilidade de garanhões. Em humanos, Jamsai et al. (2008) identificaram três SNPs não sinônimos no gene CRISP2. Embora nenhum dos polimorfismos identificados tenha mostrado associação significativa com infertilidade, estudos funcionais sugerem que o polimorfismo responsável pela troca de aminoácidos na posição 196 possa comprometer a função protéica.

\section{Polimorfismo do HTR1A}

$\mathrm{Na}$ busca por polimorfismos no gene HTR $1 A$ eqüino, Momozawa et al. (2007) seqüenciaram o cDNA proveniente do cérebro de 10 cavalos Puro Sangue Inglês não relacionados geneticamente e encontraram duas trocas não sinônimas de nucleotídeos com algum potencial de provocar alterações fenotípicas, entre as quais a conservativa AB_264325:c.771G $>$ C, aqui estudada. Este polimorfismo do HTR1A pode apresentar importância fisiológica em relação à características de comportamento ao ser responsável pela troca de um ácido glutâmico por ácido aspártico na posição 257 (Glu257Asp) da seqüência presumida de aminoácidos da cadeia polipeptídica do receptor de serotonina de eqüinos.

Para o polimorfismo supracitado, foram encontrados os alelos $\mathrm{C}$ e $\mathrm{G}$ na amostra de animais estudados. O alelo $\mathrm{G}$, quase fixado, prevaleceu sobre o C. Desta forma, o genótipo GG apresentou alta freqüência em relação ao genótipo heterozigoto. O genótipo CC não foi observado (Tabela 2). O genótipo GG foi caracterizado pela presença de dois fragmentos com 268 e 164 pb. Por sua vez, o genótipo heterozigoto $\mathrm{CG}$ foi caracterizado pela presença de três fragmentos com 432, 268, $164 \mathrm{pb}$ (Figura 2). De acordo com o mapa de restrição, o genótipo $\mathrm{CC}$, não identificado no conjunto de animais analisado, seria caracterizado pela presença de um fragmento contendo $432 \mathrm{pb}$. Da mesma forma que para o polimorfismo do CRISP1, o método de PCR-RFLP apresentou-se apropriado para a genotipagem do SNP AB_264325:c.771G $>$ C do HTR1A, o que permitirá a expansão da análise desse polimorfismo em cavalos.

Não foram encontrados relatos de freqüências alélicas e genotípicas para o SNP AB_264325:c.771G $>C$ do HTR1A em eqüinos. A alta freqüência do alelo $G$ deixa evidente o pequeno potencial de aplicação deste marcador em estudos de associação. Isto se deve ao fato de que caso o alelo $\mathrm{G}$ fosse favorável para características 
de temperamento, já estaria muito perto de estar fixado. Se, por outro lado, o alelo $\mathrm{C}$ trouxesse alguma vantagem, provavelmente se encontraria em freqüência mais elevada devido à seleção indireta. O teste do Qui-quadrado envolvendo as freqüências genotípicas observadas e esperadas mostrou que a população estudada de Mangalarga encontra-se em equilíbrio de Hardy-Weinberg para o loco que contém o polimorfismo do gene $H T R 1 A$, uma vez que, a $5 \%$ de significância, o valor do Qui-quadrado calculado $(0,034)$ foi menor que o tabelado $(3,84)$. O teste de significância de Slatkin para a neutralidade seletiva de Ewens-Watterson aplicado ao polimorfismo do gene HTR $1 A$ foi não significativo $(\mathrm{p}=0,666)$ (Tabela 3), demonstrando que não há indicativo de acasalamentos preferenciais ou de seleção em favor de um dos alelos. Neste sentido, as estimativas dos parâmetros genético-populacionais obtidos para o SNP AB_264325:c.771G $>$ C do HTR1A na amostra estudada de Mangalarga desestimulam a sua aplicação em estudos de associação com características de importância na raça.

Tabela 3. Teste F de neutralidade seletiva de Ewens-Wattersona e significância de Slatkin para os sítios polimórficos dos genes HTR1A e SLC6A4 em amostra representativa da população de eqüinos da raça Mangalarga do Estado de São Paulo.

\begin{tabular}{|c|c|c|c|c|c|c|c|c|}
\hline \multirow{2}{*}{ Polimorfismo } & \multirow{2}{*}{$\mathbf{N}$} & \multirow{2}{*}{$\begin{array}{c}\mathbf{N}^{\circ} \\
\text { alelos }\end{array}$} & \multicolumn{2}{|c|}{ Interv. Conf. de F } & \multirow{2}{*}{ F obs. } & \multirow{2}{*}{$F$ esp. } & \multirow{2}{*}{$F \mathbf{n d}^{\mathrm{b}}$} & \multirow{2}{*}{$P$} \\
\hline & & & Inf. & Sup. & & & & \\
\hline AB_264325:c.771G $>\mathrm{C}(H T R 1 A)$ & 302 & 2 & 0,500 & 0,993 & 0,967 & $\begin{array}{c}0,841 \\
\pm 0,167\end{array}$ & 0,754 & 0,666 \\
\hline AB_098561:c.1470G $>$ A $(S L C 6 A 4)$ & 302 & 2 & 0,500 & 0,993 & 0,848 & $\begin{array}{c}0,841 \\
\pm 0,167\end{array}$ & 0,039 & 0,386 \\
\hline
\end{tabular}

a Intervalo de $F$ com $95 \%$ de confiança, obtido com 1.000 .000 de simulações. ${ }^{\text {b }}$ Desvio normalizado entre $F$ observado e $F$ esperado.

Fonte: Elaboração dos autores.

Figura 2. Padrão de bandas obtido na análise por PCR-RFLP e eletroforese em gel de agarose a $2 \%$ para o polimorfismo AB_264325:c.771G $>C$ do gene HTR1A eqüino. M indica o padrão molecular de $100 \mathrm{pb}$, ND DNA amplificado não digerido pela enzima $A l u \mathrm{I}$ (432 pb) e CG e GG os genótipos decorrentes da digestão dos produtos amplificados pela enzima AluI. Os números ao lado direito da figura indicam o tamanho dos fragmentos de DNA em pares de bases.

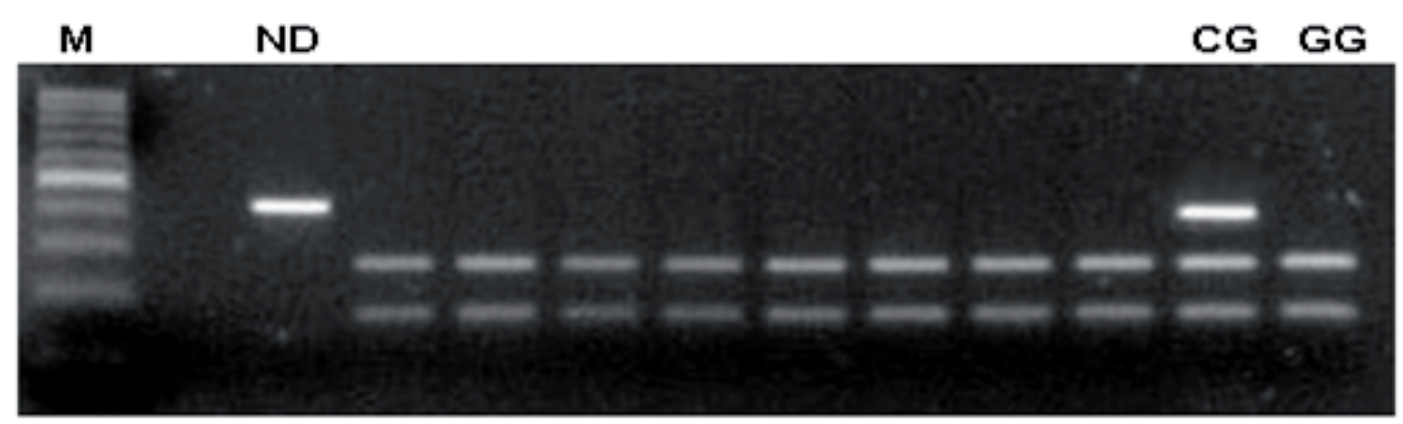

Fonte: Elaboração dos autores. 
Não foram encontrados na literatura resultados de estudos de associação entre características comportamentais e polimorfismos do gene HTR $1 A$ em eqüinos, entretanto em cães e em humanos, pesquisas com este gene e outros da família foram há pouco realizados. Van den Berg et al. (2008) analisaram o efeito de polimorfismos dos genes HTR $1 A$, HTR $1 B$ e HTR2A, entre outros, em relação ao comportamento agressivo em cães da raça Golden Retriever, não observando qualquer efeito significativo. Em revisão bibliográfica, realizada por Drago, Ronchi e Serretti (2008), foram encontrados 27 SNPs associados ao gene HTR $1 A$ humano, sendo alguns destes causadores de trocas sinônimas e não sinônimas. Estas variações têm sido estudadas em transtornos psiquiátricos, todavia ainda sem resultados definitivos (DRAGO; RONCHI; SERRETTI, 2008).

\section{Polimorfismo do SLC6A4}

Em eqüinos, Momozawa et al. (2006) determinaram a seqüência e a localização cromossômica do gene SLC6A4 e identificaram quatro SNPs, incluindo o AB_098561:c.1470G>A, analisado no presente trabalho, entre as seqüências de cDNA de uma dezena de cavalos Puro Sangue Inglês não relacionados geneticamente. Embora este polimorfismo esteja localizado em região gênica codificante, não é responsável por alteração de aminoácidos na cadeia peptídica. Mesmo assim, pode ser responsável por alterações fenotípicas, uma vez que tem a possibilidade de modificar a estrutura secundária do RNA mensageiro e consequentemente a expressão gênica. Por outro lado, pode estar em desequilíbrio de ligação com a variação funcional.

Considerando-se o mencionado polimorfismo, foram detectados na amostra de animais estudados os alelos A e G. O alelo G apresentou freqüência extremamente alta em relação ao G. Como conseqüência, o genótipo GG também apresentou freqüência alta em relação ao genótipo heterozigoto. O genótipo AA não foi observado (Tabela 2).
Assim como descrito por Momozawa et al. (2006), o genótipo GG foi caracterizado pela presença de dois fragmentos com 302 e 57 pb. O genótipo heterozigoto AG foi caracterizado pela presença de três fragmentos de 359, 302 e 57 pb. O genótipo $\mathrm{AA}$, não identificado na população estudada, seria caracterizado pela presença de fragmento único contendo $359 \mathrm{pb}$.

As freqüências alélicas obtidas para o polimorfismo do gene SLC6A4 eqüino na amostra estudada estão muito próximas das encontradas por Momozawa et al. (2006) em cavalos da raça Puro Sangue Inglês $(0,09$ para o alelo A e 0,91 para o G). O teste do Qui-quadrado demonstrou que a população estudada de Mangalarga encontra-se em equilíbrio de Hardy-Weinberg para o loco que abriga o polimorfismo do gene SLC6A4, uma vez que, a 5\% de significância, o valor do Qui-quadrado calculado $(1,075)$ foi menor que o tabelado $(3,84)$. O teste de significância de Slatkin para a neutralidade seletiva de Ewens-Watterson foi não significativo $(\mathrm{p}=0,386)$ para o polimorfismo do gene SLC6A4 (Tabela 3), mostrando que não há indicativo de acasalamentos preferenciais ou de seleção em favor de um dos alelos. Neste sentido, ambos os testes apontaram para a não aplicabilidade do polimorfismo do gene SLC6A4 em estudos de associação entre marcadores e características de interesse na Mangalarga. Estes resultados, assim como os obtidos para os outros dois SNPs analisados neste trabalho, demonstram a importância de estudos de caracterização de parâmetros genético-populacionais de polimorfismos em diferentes raças da espécie de interesse, previamente aos estudos de associação entre marcadores moleculares e características de importância, a fim de que não ocorra consumo de recursos sem proveito na medição de fenótipos que não poderão ser confrontados com variações específicas do DNA.

No único trabalho de associação realizado com o polimorfismo AB_098561:c.1470G $>$ A do SLC6A4 em eqüinos, Momozawa et al. (2006) não encontraram resultados positivos ao 
analisarem o efeito de haplótipos formados pelos SNPs identificados no gene sobre a característica ansiedade na raça Puro Sangue Inglês. Em cães Golden Retriever, Van den Berg et al. (2008) não identificaram relação entre variantes do gene e agressividade. De forma diferente, variações no SLC6A4 humano têm sido associadas à depressão, ansiedade, transtorno bipolar, suicídios, desordens alimentares e de abuso de substâncias, autismo, déficit de atenção/hiperatividade e desordens neurodegenerativas (MURPHY; LESCH, 2008).

\section{Conclusões}

Com base nos resultados encontrados, podese concluir que: (1) o método de PCR-RFLP mostrou-se adequado para a genotipagem dos SNPs AJ_315378:c.110A $>$ GeAB_264325:c.771G $>$ C dos genes CRISPI e HTRIA eqüino, respectivamente. Entretanto, o polimorfismo do CRISP1 provavelmente não ocorre em eqüinos Mangalarga, impossibilitando estudos de associação com o marcador de DNA na raça; (2) as estimativas dos parâmetros genético-populacionais obtidos para os polimorfismos AB_264325:c.771G $>$ C do gene HTR1A e AB_098561:c.1470G>A do gene SLC6A4 na amostra de animais analisada desencorajam a realização de pesquisas visando a associação entre os marcadores e características relacionadas ao temperamento na raça estudada.

\section{Agradecimentos}

À Fundação para o Desenvolvimento da Unesp (Fundunesp) e ao Conselho Nacional de Desenvolvimento Científico e Tecnológico (CNPq) pelo suporte financeiro concedido. Aos criadores, representados na pessoa de Raul Sampaio Almeida Prado, por disponibilizar dos animais para a pesquisa.

\section{Aprovação da comissão de ética}

Os procedimentos envolvendo animais foram realizados de acordo com a legislação brasileira para o bem-estar animal (protocolo $n^{\circ}$ 111/2008 expedido pela Câmara de Ética em Experimentação Animal - CEEA, da Faculdade de Medicina Veterinária e Zootecnia da Unesp, Botucatu/SP - Brasil).

\section{Referências}

DRAGO, A.; RONCHI, D. D.; SERRETTI, A. 5-HT gene variants and psychiatric disorders: a review of current literature and selection of SNPs for future studies. International Journal of Neuropsychopharmacology, Cambridge, v. 11, n. 5, p. 701-721, 2008.

EVANS, J. W. Horses: a guide to selection, care and enjoyment. 2. ed. São Francisco, EUA: WH Freeman and company, 1996. $797 \mathrm{p}$.

GIESE, A.; JUDE, R.; KUIPER, H.; PIUMI, F.; SCHAMBONY, A.; GUÉRIN, G.; DISTL, O.; TÖPFERPETERSEN, E.; LEEB, T. Molecular characterization of the equine AEG1 locus. Gene, Amsterdam, v. 292, n. 1-2, p. $65-72,2002$.

HAMANN, H.; JUDE, R.; SIEME, H.; MERTENS, U.; TÖPFER-PETERSEN, E.; DISTL, O.; LEEB, T. A polymorphism within the equine CRISP3 gene is associated with stallion fertility in Hanoverian warmblood horses. Animal Genetics, Oxford, v. 38, n. 3, p. 259-264, 2007.

JAMSAI, D.; REILLY, A.; SMITH, S. J.; JAMSAI, D.; REILLY, A.; SMITH, S. J.; GIBBS, G. M.; BAKER, H. W. G.; MCLACHLAN, R. I.; KRETSER, D. M.; O'BRYAN, M. K. Polimorphisms in the human cysteinerich secretory protein 2 (CRISP2) gene in Australian men. Human Reproduction, Oxford, v. 23, n. 9, p. 21512159, 2008.

LANCASTER, A. K.; SINGLE, R. M.; SOLBERG, O. D.; NELSON, M. P.; THOMSON, G. PyPop update - a software pipeline for large-scale multilocus population genomics. Tissue Antigens, Copenhagen, v. 69, n. 1, p. 192-197, 2007.

MOMOZAWA, Y.; TAKEUCHI, Y.; TOZAKI, T.; KIKUSUI, T.; HASEGAWA, T.; RAUDSEPP, T.; CHOWDHARY, B.; KUSUNOSE, R.; MORI, 
Y. Polimorphism identification, RH mapping, and association analysis with the anxiety trait of the equine serotonin transporter (SLC6A4) gene. Journal of Veterinary Medical Science, Tokyo, v. 68, n. 6, p. 619621, 2006.

MOMOZAWA, Y.; TAKEUCHI, Y.; TOZAKI, T.; KIKUSUI, T.; HASEGAWA, T.; RAUDSEPP, T.; CHOWDHARY, B.; KUSUNOSE, R.; MORI, Y. SNP detection and radiation hybrid mapping horses of nine candidate genes for temperament. Animal Genetics, Oxford, v. 38, n. 1, p. 81-91, 2007.

MOTA, M. D. S.; ALMEIDA PRADO, R. S. Estudo genético da pontuação total em eqüinos da raça Mangalarga. Archivos de Zootecnia, Córdoba, v. 54, n. 205, p. 25-30, 2005.

MOTA, M. D. S.; ALMEIDA PRADO, R. S.; MADUREIRA, D. G. F. Estimativa de parâmetros genéticos para deslocamento em cavalos da raça Mangalarga. Archivos de Zootecnia, Córdoba, v. 55, n. 210, p. 207-210, 2006.

MOTA, M. D. S.; GIANNONI, M. A. Efeitos genéticos e de ambiente sobre alguns caracteres de locomoção e desenvolvimento em eqüinos da raça Mangalarga. Revista Portuguesa de Ciências Veterinárias, Lisboa, v. 89, n. 512, p. 191-196, 1994.

MURPHY, D. L.; FOX, M. A.; TIMPANO, K. R.; MOYA, P. R.; REN-PATTERSON, R.; ANDREWS, A. M.; HOLMES, A.; LESCH, K. P.; WENDLAND, J. R. How the serotonin story is being rewritten by new gene-based discoveries principally related to $S L C 6 A 4$, the serotonin transporter gene, wich functions to influence all cellular serotonin systems. Neuropharmacology, Oxford, v. 55, n. 6, p. 932-960, 2008.

MURPHY, D. L.; LESCH, K. P. Targeting the murine serotonin transporter: insights into human neurobiology. Neuroscience, Oxford, v. 9, n. 2, p. 85-96, 2008.

ROZEN, S.; SKALETSKY, H. Primer3 on the www for general users and for biologist programmers. Methods in Molecular Biology, Totowa, v. 132, n. 3, p. 365-386, 2000.

SLATKIN, M. A correction to the exact test based on the Ewens sampling distribution. Genetic Research, Cambridge, v. 68, n. 3, p. 259-260, 1996.

TAVEIRA, R. Z.; MOTA, M. D. S. Genetic and quantitative evaluation of breeding traits in Thoroughbred mares. Revista Electronica de Veterinaria, Málaga, v. 8, n. 5, p. 1-11, 2007.

VAN DEN BERG, L.; VOS-LOOHUIS, M.; SCHILDER, M. B. H.; VAN OOST, B. A.; HAZEWINKEL, H. A. W.; WADE, C. M.; KARLSSON, E. K.; LINDBLAD-TOH, K.; LIINAMO, A. E.; LEEGWATER, P. A. J. Evaluation of the serotonergic genes HTR1A, HTR1B, HTR2A, and SLC6A4 in aggressive behavior of golden retriever. Behavior Genetics, Nova York, v. 38, n. 1, p. 55-66, 2008.

YEH, F. C., YANG, R. C., BOYLE, T. Popgene version 1.32. Microsoft windows - based freeware for population genetic analysis. Canada: University of Alberta, 1999. 